\title{
A combination of curcumin, vorinostat and silibinin reverses $A \beta$-induced nerve cell toxicity via activation of AKT-MDM2-p53 pathway
}

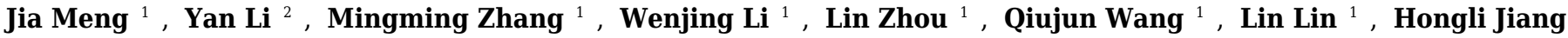 \\ Corresp., 1 , Wenliang Zhu Corresp. 3 \\ 1 Department of General Medicine, Second Affiliated Hospital of Harbin Medical University, Harbin, China \\ 2 Department of Pharmacy, Fourth Affiliated Hospital of Harbin Medical University, Harbin, China \\ 3 Department of Pharmacy, Second Affiliated Hospital of Harbin Medical University, Harbin, China \\ Corresponding Authors: Hongli Jiang, Wenliang Zhu \\ Email address: jianglihong2006@163.com, zhuwenliang@hrbmu.edu.cn
}

Alzheimer's disease (AD) is a significant health issue for the elderly and becoming increasingly common as the global population ages. Although many efforts have been made to elucidate its pathology, there is still a lack of effective clinical anti-AD agents. Previous research has shown the neuroprotective properties of a combination of curcumin and vorinostat. In this study, nine other neuroprotective agents were investigated to examine whether a three-drug combination of curcumin, vorinostat, and a new drug is more advantageous than the previous two-drug combination in alleviating amyloid beta $(A \beta)$-induced nerve cell toxicity. Cell viability assay was performed to screen these agents, and further validation tests, including determination of cellular oxidative stress, apoptosis, and activity of the AKT/MDM2/p53 pathway, were performed. Among the nine candidate compounds, only silibinin at $1 \mu \mathrm{M}$ reduced $A \beta_{25-35}$-induced toxicity in PC12 cells. The neuroprotective effects of $1 \mu \mathrm{M}$ silibinin in combination with $5 \mu \mathrm{M}$ curcumin and $0.5 \mu \mathrm{M}$ vorinostat (CVS) was shown in PC12 cells, in which it decreased apoptosis and oxidative stress marker levels that were increased by $20 \mu \mathrm{M} \mathrm{A} \beta_{25-35}$. Western blotting results showed that CVS pretreatment significantly increased the phosphorylation of AKT, BAD, and MDM2, which resulted in decreased intracellular expression of p53. Further, immunofluorescence results showed reduced p53 levels in the nuclei of PC12 cells following CVS pretreatment, indicating a reduction in the p53-mediated transcriptional activity associated with $A \beta_{25-35}$ exposure. In conclusion, our findings suggested that pretreatment with CVS protected PC12 cells from $A \beta_{25-35}$-induced toxicity through modulation of the AKT/MDM2/p53 pathway. Thus, CVS may present a new therapeutic option for treating AD. 
1 A combination of curcumin, vorinostat and silibinin reverses $A \beta$-induced nerve cell toxicity via

2

3

4 Jia Meng ${ }^{1}$, Yan $\mathrm{Li}^{2}$, Mingming Zhang ${ }^{1}$, Wenjing Li ${ }^{1}$, Lin Zhou ${ }^{1}$, Qiujun Wang ${ }^{1}$, Lin Lin ${ }^{1}$, Hongli Jiang ${ }^{1, *}$,

5 Wenliang $\mathrm{Zhu}^{3, *}$

$6 \quad{ }^{1}$ Department of General Medicine, Second Affiliated Hospital of Harbin Medical University, Harbin, China

$7 \quad{ }^{2}$ Department of Pharmacy, Fourth Affiliated Hospital of Harbin Medical University, Harbin, China

$8 \quad{ }^{3}$ Department of Pharmacy, Second Affiliated Hospital of Harbin Medical University, Harbin, China

9 Corresponding author information

10

*To whom correspondence should be addressed. Address: Xuefu Road 246, Harbin 150086, Heilongjiang,

11 China; Hongli Jiang: Tel/Fax: 86-451-8629-7273; E-mail: jianglihong2006@163.com; Wenliang Zhu:

12 Tel/Fax: 86-451-8660-5765; E-mail: zhuwenliang@hrbmu.edu.cn.

13

14

15

16

17

18

\section{ABSTRACT}

20 Alzheimer's disease (AD) is a significant health issue for the elderly and becoming increasingly common

21 as the global population ages. Although many efforts have been made to elucidate its pathology, there is 
22 still a lack of effective clinical anti-AD agents. Previous research has shown the neuroprotective properties

23 of a combination of curcumin and vorinostat. In this study, nine other neuroprotective agents were

investigated to examine whether a three-drug combination of curcumin, vorinostat, and a new drug is more advantageous than the previous two-drug combination in alleviating amyloid beta (A $\beta)$-induced nerve cell toxicity. Cell viability assay was performed to screen these agents, and further validation tests, including determination of cellular oxidative stress, apoptosis, and activity of the AKT/MDM2/p53 pathway, were performed. Among the nine candidate compounds, only silibinin at $1 \mu \mathrm{M}$ reduced $\mathrm{A} \beta_{25-35}$-induced toxicity in PC12 cells. The neuroprotective effects of $1 \mu \mathrm{M}$ silibinin in combination with $5 \mu \mathrm{M}$ curcumin and 0.5 $\mu \mathrm{M}$ vorinostat (CVS) was shown in PC12 cells, in which it decreased apoptosis and oxidative stress marker levels that were increased by $20 \mu \mathrm{M} \mathrm{A} \beta_{25-35}$. Western blotting results showed that CVS pretreatment significantly increased the phosphorylation of AKT, BAD, and MDM2, which resulted in decreased intracellular expression of p53. Further, immunofluorescence results showed reduced p53 levels in the nuclei of PC12 cells following CVS pretreatment, indicating a reduction in the p53-mediated transcriptional activity associated with $A \beta_{25-35}$ exposure. In conclusion, our findings suggested that pretreatment with CVS protected PC12 cells from $\mathrm{A} \beta_{25-35}$-induced toxicity through modulation of the AKT/MDM2/p53 pathway. Thus, CVS may present a new therapeutic option for treating AD.

\section{INTRODUCTION}

Alzheimer's disease (AD) is a progressive neurodegenerative disorder characterized by extracellular deposition of amyloid beta $(\mathrm{A} \beta)$ plaques and intracellular aggregation of neurofibrillary tangles (SanabriaCastro, et al., 2017). AD is the most common form of dementia among the elderly (Mattson, 2004), and is characterized by severe cognitive impairment and memory loss. AD is the fifth-leading cause of death in 
43

44 (Alzheimer's Association, 2016). There are currently more than 7 million AD patients in China, and this

people over the age of 65 years, and it is estimated that 5.4 million people have AD in the United States number is growing (Chan et al., 2013; Jia et al., 2014). However, these issues are not specific to the United

States and China because other countries are also facing problems associated with aging population. The global growth of AD patients has contributed to a worldwide increase in nursing demand and economic burden (Jia et al., 2018). If no effective measures are taken, it is objectively estimated that one among every 85 individuals will suffer from AD by the middle of this century (Brookmeyer et al., 2007).

Despite the rapidly increasing prevalence of $\mathrm{AD}$, there is a severe lack of therapeutic strategies to prevent $\mathrm{AD}$ or to reverse the development of $\mathrm{A} \beta$ plaques (Agatonovic-Kustrin et al., 2018). To date, only three acetylcholinesterase inhibitors (donepezil, galantamine, and rivastigmine) and one noncompetitive Nmethyl-D-aspartate receptor antagonist (memantine) have been approved by the U.S. Food and Drug Administration (FDA) as treatments for AD (Guzior et al., 2015). Unfortunately, these approved drugs only elicit modest symptomatic improvement and temporary cognitive improvement in half of the patients with AD (Blennow et al., 2006). Given such limited options, a significant amount of research has focused on alternative therapies for $\mathrm{AD}$. As a result, several natural compounds have been shown to exert promising neuroprotective effects mediated through the p53 pathway, making them promising candidate drugs for treating AD (Jazvinšćak et al., 2018).

One such example is curcumin, a natural flavonoid isolated from Rhizoma Curcumae Longae, which exerts neuroprotective effects against $A \beta$-induced neurotoxicity in both cell and animal models (Potter, 2013). However, no clinical studies have shown the efficacy of oral curcumin in treating AD, which is likely due to the low bioavailability of curcumin in humans (Ringman et al., 2012). However, our research 
64

65

66

67

\section{MATERIALS and METHODS} may be increased. curcumin and vorinostat.

group has shown that curcumin and vorinostat, a histone deacetylase inhibitor, exert synergistic neuroprotective effects against A $\beta$ toxicity in PC12 cells (Meng et al., 2014). The in vitro model of Amyloid beta-25-35 (A $\left.\beta_{25-35}\right)$-induced PC12 cells used in the study is widely accepted and adopted by researchers in the field of neuroprotective agents (Kim et al., 2015; Li et al., 2017; Zhao et al., 2018). Our previous study also suggested that co-administration of curcumin and vorinostat protects neural cells from A $\beta$-induced apoptosis by maintaining high phosphorylation of AKT serine/threonine kinase (AKT). It is noteworthy that the effect of the drug combination on the expression and transcriptional activity of the tumor protein p53 was not investigated. Given that simultaneous accumulation and cooperation of $A \beta$ and p53 have been observed in patients with $\mathrm{AD}$, it is likely that p53 plays a critical role in $\mathrm{AD}$ progression (Ohyagi et al., 2005). Furthermore, we suspect that through these synergistic mechanisms, the bioavailability of curcumin

In the present study, the effects of curcumin were assessed in combination with other natural compounds to elucidate whether its neuroprotective effect is mediated through activation of the AKT/MDM2 protooncogene 2 (MDM2)/p53 pathway. Furthermore, because many natural compounds such as resveratrol, piceatannol, genistein, quercetin, kaempferol, luteolin, apigenin, daidzein, and silibinin have been shown to have neuroprotective effects (Wang et al., 2018; Fu et al., 2016; You et al., 2017; Ansari et al., 2009; Pate et al., 2017; Sawmiller et al., 2014; Zhao et al., 2013; Westmark et al., 2013; Duan et al., 2015), we explored whether the addition of one of these compounds would further enhance the neuronal benefit of 
85

86

87

\section{Materials}

$\mathrm{A} \beta_{25-35}$ peptide was purchased from Chinapeptides Corporation (Shanghai, China), diluted to a stock concentration of $1 \mathrm{mM}$ in double-distilled $\mathrm{H}_{2} \mathrm{O}$, and incubated at $37{ }^{\circ} \mathrm{C}$ for 7 days to induce aggregation. Following incubation, stock solution of $A \beta_{25-35}$ was diluted in cell culture media to a final concentration of $20 \mu \mathrm{M}$, as described previously (Jia et al., 2014). Unless noted otherwise, all additional chemicals and reagents were purchased from Sigma Aldrich, Inc. (St. Louis, MO, USA).

\section{Cell culture and treatment}

Rat pheochromocytoma (PC12) cells were grown on tissue culture-treated plates with Dulbecco's modified Eagle's medium/nutrient mixture F-12 (DMEM/F-12) supplemented with 7\% fetal bovine serum (FBS) and $1 \%$ penicillin-streptomycin. The cells were maintained at $37{ }^{\circ} \mathrm{C}$ in an incubator with $5 \% \mathrm{CO}_{2}$. After reaching $80 \%$ confluence, the cells were cultured in serum-free medium for $12 \mathrm{~h}$, and then pretreated for 1 $\mathrm{h}$ with either a single compound of interest or a combination of compounds. After the pretreatment, the cells were exposed to $A \beta_{25-35}$ peptide for $24 \mathrm{~h}$.

\section{Cell viability assay}

Cell viability was measured using the 3-[4,5-dimethylthiazol-3-yl]-2,5-diphenyltetrazolium bromide (MTT) assay. In brief, cells were seeded in a 96-well plate at a density of $1 \times 10^{4}$ cells/well and treated with compound(s) of interest, whereas the control cells were treated with an equal volume of DMEM-F12 with $7 \%$ FBS. Following a 24-h incubation, $10 \mu \mathrm{L}$ of MTT $(5 \mathrm{mg} / \mathrm{mL})$ was added to each well, which was then incubated at $37^{\circ} \mathrm{C}$ for $4 \mathrm{~h}$. The medium was then discarded and replaced with $100 \mu \mathrm{L}$ dimethyl sulfoxide (DMSO) to dissolve the crystals. Next, optical density was measured at $490 \mathrm{~nm}$ using a multi-mode microplate reader (SpectraMax M5; Molecular Devices Company, California, United States). 
106

107

108

109

110

111

112

113

114

115

116

117

118

119

120

121

122

123

124

125

126

127

128

\section{Determination of reactive oxygen species (ROS) levels}

PC12 cells were pretreated with the following drug combinations for $1 \mathrm{~h}$ at $37^{\circ} \mathrm{C}$ in DMEM: curcumin $(5$ $\mu \mathrm{M})$ alone; a two-drug combination of curcumin $(5 \mu \mathrm{M})$ and vorinostat $(0.5 \mu \mathrm{M})$; or a three-drug combination of curcumin $(5 \mu \mathrm{M})$, vorinostat $(0.5 \mu \mathrm{M})$, and silibinin $(1 \mu \mathrm{M})$. Following the pretreatment, $\mathrm{A} \beta_{23-25}$ peptide was added to induce cell apoptosis, and intracellular ROS generation was assessed using a reactive oxygen species assay kit (Nanjing Jiancheng Institute of Biotechnology, Nanjing, China) according to the manufacturer's instructions. In brief, PC12 cells were washed twice with phosphate-buffered saline (PBS) and then incubated with $10 \mu \mathrm{M} 2^{\prime}, 7^{\prime}$-dichlorodihydrofluorescein diacetate (DCFH-DA) dye in serumfree DMEM-F12 for $1 \mathrm{~h}$ at $37^{\circ} \mathrm{C}$. The cells were washed with PBS, and fluorescence was observed at 488 $\mathrm{nm}$ and recorded using confocal microscopy. Semi-quantification of ROS levels was performed by using the ImageJ software.

\section{Measurement of superoxide dismutase (SOD) and malondialdehyde (MDA) levels}

Briefly, the treated PC12 cells were harvested and lysed in lysis buffer, and the resulting cell lysates were centrifuged at $3,000 \times \mathrm{g}$ for $10 \mathrm{~min}$ at $4{ }^{\circ} \mathrm{C}$. The resulting supernatant was collected for enzyme activity analysis. Levels of SOD and MDA were determined through the nitroblue tetrazolium assay using a total SOD Detection Kit (Beyotime Institute of Biotechnology, Shanghai, China) and MDA assay kit (Jiancheng Institute of Biotechnology), according to the manufacturers' instruction. Protein concentration was determined using a BCA Protein Assay Kit (Beyotime Institute of Biotechnology). One unit of SOD and MDA was defined as the amount of protein. SOD and MDA values were expressed as enzyme activity per milligram protein $(\mathrm{U} / \mathrm{mg})$.

\section{Western blotting assay}

PC12 cells were washed with PBS, lysed with ice-cold radioimmunoprecipitation assay (RIPA) lysis buffer, and added to phenylmethanesulfonyl fluoride. The mixture was then centrifuged for $15 \mathrm{~min}$ at $14,000 \times g$ 
and $4{ }^{\circ} \mathrm{C}$. Total cellular proteins in the supernatants were measured using a BCA protein assay kit (Beyotime Institute of Biotechnology) according to the manufacturer's instructions. Proteins were then separated using $10 \%$ sodium dodecyl sulfate-polyacrylamide gel electrophoresis, and protein bands were transferred to a polyvinylidene difluoride membrane (Millipore Corp., Bedford, MA, USA). Next, the membrane was blocked with 5\% non-fat milk diluted in $1 \times$ tris-buffered saline with $0.1 \%$ Tween $1 \mathrm{~h}$ at room temperature $\left(24^{\circ} \mathrm{C}\right)$. The membranes were then incubated for $12 \mathrm{~h}$ at $4^{\circ} \mathrm{C}$ with the following primary antibodies: rabbit polyclonal phospho-MDM2 antibody ( $p$-MDM2; 1:1000; Cell Signaling Technology, Danvers, MA, USA), mouse monoclonal p53 antibody (1:1000; Cell signaling Technology), rabbit monoclonal phospho-AKT (ser473) antibody ( $p$-AKT; 1:1000; Cell Signaling Technology), rabbit monoclonal phospho-BAD (Ser112) antibody ( $p$-BAD; 1:1000; Cell Signaling Technology), and mouse monoclonal $\beta$-actin antibody (1:5000; Abcam, Cambridge, MA, USA). The membranes were then washed and incubated at room temperature (24 $\left.{ }^{\circ} \mathrm{C}\right)$ for $1 \mathrm{~h}$ with goat anti-rabbit IRDye ${ }^{\circledR} 800 \mathrm{CW}(1: 10000$; Li-Cor Biosciences, Lincoln, NE, USA) or goat anti-mouse IRDye ${ }^{\circledR} 800 \mathrm{CW}(1: 10000$; Li-Cor Biosciences). Proteins were visualized using the Odyssey Infrared Imager System (Li-Cor Biosciences), and the odyssey v1.2 software was used to quantify protein by measuring band intensity (area $\times$ optical density) in each group, with $\beta$-actin as an internal control.

\section{Transferase-mediated deoxyuridine triphosphate biotin nick-end labeling (TUNEL) assay}

During apoptosis, cleavage of genomic DNA yields double-stranded DNA breaks that are identifiable by labeling the free $3^{\prime}-\mathrm{OH}$ termini with modified nucleotides in an enzymatic reaction; the TUNEL assay is based on this principle. In brief, PC12 cells were grown on confocal dishes (NEST, Wuxi, China) in DMEM-F12 for $24 \mathrm{~h}$, and then pretreated with the compounds of interest alone or in combinations for $1 \mathrm{~h}$. 
150 The pretreated cells were then exposed to $20 \mu \mathrm{M} \mathrm{A} \beta_{25-35}$ for $24 \mathrm{~h}$ at $37{ }^{\circ} \mathrm{C}$ and $5 \% \mathrm{CO}_{2}$. The cells were

151 washed twice with PBS and then fixed with 4\% paraformaldehyde (PFA) at room temperature $\left(24^{\circ} \mathrm{C}\right)$. The

152 fixed cells were washed twice with PBS buffer, treated with $0.1 \%$ TritonX-100 to permeate cells, and then

washed twice with PBS. Next, TUNEL reaction mixture (Beyotime Institute of Biotechnology) was added

to the cells, which were then incubated for $60 \mathrm{~min}$ at $37{ }^{\circ} \mathrm{C}$ in a dark, humidified environment. Negative

controls were prepared with equal volumes of labeling solution. After this incubation, the confocal dishes

(NEST) were rinsed twice with PBS. Finally, the cells were analyzed using a confocal Laser Scanning

Biological microscope FV1000 (Olympus, Tokyo, Japan) at an excitation wavelength of $488 \mathrm{~nm}$.

158

159

160

161

162

163

164

165

166

167

168

169

170

\section{Immunofluorescence staining assay}

Colocalization of p53 and MDM2 proteins was examined by immunofluorescence staining of the treated PC12 cells. In brief, PC12 cells were cultured on confocal dishes (NEST) at $37^{\circ} \mathrm{C}$ for $24 \mathrm{~h}$. After treatments with $\mathrm{A} \beta_{25-35}$, curcumin $(5 \mu \mathrm{M})$, vorinostat $(0.5 \mu \mathrm{M})$, and silibinin $(1 \mu \mathrm{M})$, as described previously, the cells were fixed with $4 \%$ PFA for 15 min at room temperature $\left(24{ }^{\circ} \mathrm{C}\right)$, washed twice with PBS, and incubated with $0.1 \%$ Triton-X 100 for $15 \mathrm{~min}$ at room temperature $\left(24{ }^{\circ} \mathrm{C}\right)$. The cells were then blocked with $1 \%$ bovine serum albumin in PBS for $30 \mathrm{~min}$, and subsequently incubated with antibodies against p53 (1:1000; Cell Signaling Technology) and MDM2 (1:400; Cell Signaling Technology) at $4{ }^{\circ} \mathrm{C}$ for $12 \mathrm{~h}$ with mild shaking. The cells were washed twice with PBS, then incubated with a secondary antibody at room temperature $\left(24{ }^{\circ} \mathrm{C}\right)$ for $1 \mathrm{~h}$; the secondary antibodies were donkey anti-rabbit 488 (1:1000; Invitrogen, Camarillo, CA, USA) and donkey anti-mouse 594 (1:1000; Invitrogen). To stain cell nuclei, the cells were incubated with $1 \mu \mathrm{g} / \mathrm{ml}$ 4',6-diamidino-2-phenylindole (DAPI) for $5 \mathrm{~min}$. Next, the cells were washed twice with PBS and observed using a confocal Laser Scanning Biological microscope FV1000 (Olympus). 


\section{Statistical analysis}

172 All experiments were repeated five times, and all values are expressed as mean \pm standard error of the mean

173 (SEM). Statistical analysis was performed using GraphPad Prism v6.0 (GraphPad Software, Inc., San

174 Diego, CA, USA). To assess differences among three or more groups, one-way analysis of variance

175 (ANOVA) with Dunnett's test was used. Values of $p<0.01$ were considered to indicate statistically

176 significant differences.

\section{RESULTS}

179

180

181

182

183

184

185

186

187

188

189

190

191

\section{Silibinin enhanced the neuroprotective effects of the combination of curcumin and vorinostat}

\section{against $A \beta_{25-35}$-induced cytotoxicity}

In the present study, nine natural compounds were investigated for synergistic activity with a drug combination of curcumin and vorinostat in $\mathrm{A} \beta_{25-35}$-treated PC12 cells. The nine compounds, each had been documented to have neuroprotective effects (Wang et al., 2018; Fu et al., 2016; You et al., 2017; Ansari et al., 2009; Pate et al., 2017; Sawmiller et al., 2014; Zhao et al., 2013; Westmark et al., 2013; Duan et al., 2015), included resveratrol, piceatannol, genistein, quercetin, kaempferol, luteolin, apigenin, daidzein, and silibinin. Our results indicated that at $1 \mu \mathrm{M}$, only silibinin showed significant neuroprotective effect against $\mathrm{A} \beta_{25-35}(p<0.01$, Figure 1A). Further, cell viability assays showed a synergistic activity between silibinin and the two-drug combination of $5 \mu \mathrm{M}$ curcumin and $0.5 \mu \mathrm{M}$ vorinostat (Figure 1B). This three-drug combination increased the ability of $\mathrm{PC} 12$ cells to tolerate $\mathrm{A} \beta_{25-35}$-induced cytotoxicity. Between the control group and the curcumin-vorinostat-silibinin (CVS) and $A \beta_{25-35}$ treatment group, no differences in either CASP3 expression or TUNEL-positive cells percentage were observed (Figures 1C and D, $p>0.01$ ). 
192

193

194

195

196

197

198

199

200

201

202

203

204

205

206

207

208

209

210

211

212

\section{Pretreatment with CVS significantly reduced oxidative stress following stimulation with}

$\mathbf{A} \boldsymbol{\beta}_{25-35}$

A significant increase in ROS production (3.6-fold relative to control) was observed in the PC12 cells treated with $20 \mu \mathrm{M} \mathrm{A} \beta_{25-35}$ (Figure 2A); however, in the cells pretreated with CVS for $1 \mathrm{~h}$, there was no significant increase in ROS generation following $\mathrm{A} \beta_{25-35}$ treatment $(p>0.01)$. Consistent with these results, $\mathrm{A} \beta_{25-35}$ significantly decreased SOD concentration (1.9 fold compared to the control) and increased MDA concentration (6.4 fold compared to the control) in PC12 cells (Figures 2B and C). However, in the cells pretreated with CVS, SOD and MDA concentrations were not significantly affected by $\mathrm{A} \beta_{25-35}(p>0.01)$.

\section{Pretreatment with CVS maintained the active status of the Akt/MDM2/p53 pathway}

Treatment of PC12 cells with $20 \mu \mathrm{M} \mathrm{A} \beta_{25-35}$ induced a significant decrease in AKT phosphorylation $(p<$ 0.001 , Figure $3 \mathrm{~A}$ ), which was correlated with a significant decrease in the expression of the downstream proteins, $p$-BAD and $p$-MDM2 (Figures 3B and C). However, in the cells pretreated with CVS, the A $\beta_{25-}$ 35 -mediated reduction of these proteins was inhibited (Figures 3A-C). Further, pretreatment with CVS was more effective than pretreatment with curcumin alone or the two-drug combination (curcumin and vorinostat) in reducing the effects of $A \beta_{25-35}$ exposure. Similarly, pretreatment of PC12 cells with CVS reduced intracellular p53 expression, which was significantly increased by $20 \mu \mathrm{M} \mathrm{A} \beta_{25-35}$ (Figure 3D). This was supported by a decrease in the increased transcriptional activity of p53 mediated by $A \beta_{25-35}$ in the cells pretreated with CVS, as shown by immunofluorescent microscopy results (Figure 4).

\section{DISCUSSION}

In the United States, approximately one in seven people aged $\geq 65$ years have $\mathrm{AD}$, and this figure jumps to 
213

214 215

approximately 50\% in those aged over 85 years (Alzheimer's Association, 2016). As the global population ages, these numbers continue to grow, making prevention and treatment of $\mathrm{AD}$ one of the most important healthcare issues of this century (Goedert and Spillantini, 2006). However, this is complicated by a severe lack of therapeutic options for AD.

It has been approximately 25 years since the amyloid hypothesis of $\mathrm{AD}$ was proposed; however, recent studies have shown that this is only a part of the story (Hardy and Higgins, 1992; Armstrong, 2013). A $\beta$ aggregation should be considered a reaction to, rather than a cause of the pathological progression of AD. The real impetus appears to be sedentary, overindulgent lifestyle causing chronic stress on the brain, which in turn accelerates brain aging (Caruso et al., 2018; Mattson and Arumugam, 2018). The clinical failure of treatment strategies involving scavenging of $A \beta$ from the brain partially supports this hypothesis regarding the pathological progression of $\mathrm{AD}$ (Citron, 2010). Further, clinical investigations suggest that approximately one in four patients with AD are not diagnosed according to the discriminant threshold levels of $\mathrm{A} \beta$ plaques and Tau tangles, yet these patients still experience severe loss of hippocampal pyramidal neurons (Mattson, 2015), suggesting that this pathology may not be the exclusive result of advanced AD. Thus, the $A \beta$-scavenging strategy is too arbitrary and focused, and drug target research from a new perspective is necessary for developing effective AD drugs.

One of the most promising approaches is the upregulation of $\mathrm{p} 53$, which has been found to be crucial to AD development (Jazvinšćak et al., 2018). Conveniently, p53 is encoded by tp53, one of the most thoroughly investigated genes in the human genome (Dolgin, 2017). Therefore, there are numerous potential drug candidates already available to modulate the p53 pathway, and they may be of use as targeted AD therapeutics. Recently, Jazvinšćak et al. suggested that natural compounds may be a source of suitable 
234 drug candidates because many natural compounds are known to regulate this pathway (Jazvinšćak et al.,

235 2018). In our study, nine natural compounds were screened for their ability to inhibit the cytotoxic effects

236 of excessive $\mathrm{A} \beta$ deposit in PC12 cells. Accordingly, $1 \mu \mathrm{M}$ silibinin showed the greatest activity in the drug

237 screening.

238 Subsequent experiments revealed that the addition of silibinin to our previously established drug combination (curcumin and vorinostat) enhanced the neuroprotective effects of this combination by activating the AKT/MDM2/p53 axis. By reconstructing the data of hippocampus gene expression in patients with AD (Blalock et al., 2004), we established an interaction network of proteins encoded by dysregulated genes in AD (Meng et al., 2014). This network clearly visualized the network hub identity of downregulated AKT. Consistently, inhibited AKT was validated to induce neuronal apoptosis (Vázquez et al., 2013). A study by Limesand and colleagues (Limesand et al., 2006) showed the functional relationship between AKT and p53, which plays a crucial role in AD pathology (Jazvinšćak et al., 2018). The authors also provided evidence of MDM2 as a critical information transmitter in the activation of AKT and suppression of p53-induced cell apoptosis.

The potent activity of this three-drug combination at low concentrations suggested synergistic drug interactions, which is consistent with the results of our previous study (Meng et al., 2014). Compared to monotherapies, synergistic drug combinations possess many inherent advantages, including lower doses, multi-target regulation, and reduced risk of drug resistance development (Zimmermann et al., 2007; Lehár et al., 2009; Jia et al., 2009). More importantly, the three drugs investigated in this study are all commercially available. Thus, the CVS treatment is economically feasible for late-stage drug development. 
255 drug (Venigalla et al., 2015). However, its poor bioavailability in humans limits its further clinical

256 application (Chin et al., 2013). Multiple strategies have been assessed to solve this issue of low

257 bioavailability. For example, formulation of curcumin-loaded nanoparticles increased curcumin

258 bioavailability, but it was associated with higher costs (Tiwari et al., 2014). Other studies have indicated

259 that a curcuminoid mixture (instead of curcumin alone) has great efficacy in the potential treatment of AD

260 (Ahmed and Gilani, 2014), suggesting that combination therapies may be an effective strategy for using

curcumin as a treatment for AD. Vorinostat, or suberoylanilidehydroxamic acid, is a histone deacetylase

inhibitor approved by the FDA as a treatment for cutaneous $\mathrm{T}$ cell lymphoma. Vorinostat may also have

potential value as a treatment for $\mathrm{AD}$ through its effects on the CREB-binding protein (CBP)/E1A-binding

protein p300 (EP300) signaling pathway (Rouaux et al., 2004). In a previous study, we showed synergistic

properties between vorinostat and curcumin in protecting PC12 cells against A $\beta$ toxicity; however,

exposure to high concentrations of vorinostat was found to be cytotoxic (Meng et al., 2014). Given this

potential cytotoxicity, we reduced its concentration from $1 \mu \mathrm{M}$ to $0.5 \mu \mathrm{M}$. Recently, several studies have

shown the neuroprotective effects of silibinin in a model of A $\beta$-treated rats (Song et al., 2017; Song et al.,

2018). Consistent with these findings, our results showed that silibinin increased the effects of the two-drug

combination in protecting neural cells from $A \beta$ toxicity.

In our study, the experiment was designed such that PC12 cells were pretreated with the drug 
276 et al., 2012), and they are associated with lower economic costs (Jia et al., 2018). Therefore, preventing

277 dementia via treatment of early-stage AD is more economically feasible than treating AD-type dementia

278 (Goedert and Spillantini, 2006).

279

280 CONCLUSIONS

281 Through a cell viability screening of nine natural compounds, we successfully identified CVS, a

282

283

284

285

286

287

288

289

290

291

292

293

294

295

296 combination of three low-concentration drugs, which had potential as an AD therapeutic. Our results

showed the strong neuroprotective ability of CVS against A $\beta$ toxicity in vitro, and that pretreatment with

CVS increased the tolerance of nerve cells to $A \beta$ toxicity. We also showed that simulated $A \beta$ aggregation

led to inactivation of the AKT/MDM2/p53 pathway, which has a critical role in AD progression. However, pretreatment with CVS maintained the active state of the pathway and ensured low transcriptional activity of p53. As a direct result of the protection provided by CVS, no significant cell apoptosis or oxidative stress occurred when PC12 cells were exposed to $\mathrm{A} \beta$ aggregation. However, this verification of the effectiveness of CVS in vitro is only the first step. Further studies in animal models are necessary to evaluate the therapeutic value of CVS for AD. In conclusion, our findings suggested that CVS is a promising prophylaxis for $\mathrm{AD}$ treatment.

\section{ACKNOWLEDGEMENT}

We thank Dr. Songbin Fu for reviewing the manuscript and giving suggestions. 
297

298

299

300

301

302

303

304

305

306

307

308

309

310

311

312

313

314

315

316

317

Agatonovic-Kustrin S, Kettle C, Morton DW. 2018. A molecular approach in drug development for

Alzheimer's disease. Biomedicine \& Pharmacotherapy 106:553-565 DOI 10.1016/j.biopha.2018.06.147.

Ahmed T, Gilani AH. 2014. Therapeutic potential of turmeric in Alzheimer's disease: curcumin or curcuminoids? Phytotherapy Research 28(4):517-525 DOI 10.1002/ptr.5030.

Alzheimer's Association. 2016. 2016 Alzheimer's disease facts and figures. Alzheimer's \& Dementia 12(4):459-509 DOI 10.1016/j.jalz.2016.03.001.

Ansari MA, Abdul HM, Joshi G, Opii WO, Butterfield DA. 2009. Protective effect of quercetin in primary neurons against Abeta(1-42): relevance to Alzheimer's disease. Journal of Nutritional Biochemistry 20(4):269-275 DOI 10.1016/j.jnutbio.2008.03.002.

Armstrong RA. 2013. What causes alzheimer's disease? Folia Neuropathologica 51(3):169-188 DOI 10.5114/fn.2013.37702.

Blennow K, de Leon MJ, Zetterberg H. 2006. Alzheimer's disease. Lancet 368(9533):387-403 DOI 10.1016/S0140-6736(06)69113-7.

Blalock EM, Geddes JW, Chen KC, Porter NM, Markesbery WR, Landfield PW. 2004. Incipient

Alzheimer's disease: microarray correlation analyses reveal major transcriptional and tumor suppressor responses. Proceedings of the National Academy of Sciences of the United States of America 101(7):21732178 DOI 10.1073/pnas.0308512100.

Brookmeyer R, Johnson E, Ziegler-Graham K, Arrighi HM. 2007. Forecasting the global burden of Alzheimer's disease. Alzheimer's \& Dementia 3(3):186-191 DOI 10.1016/j.jalz.2007.04.381.

Caruso A, Nicoletti F, Mango D, Saidi A, Orlando R, Scaccianoce S. 2018. Stress as risk factor for Alzheimer's disease. Pharmacological Research 132:130-134 DOI 10.1016/j.phrs.2018.04.017. 
318

319

320

321

322

323

324

325

326

327

328

329

330

331

332

333

334

335

336

337

338

Chan KY, Wang W, Wu JJ, Liu L, Theodoratou E, Car J, Middleton L, Russ TC, Deary IJ, Campbell

H, Wang W, Rudan I, Global Health Epidemiology Reference Group (GHERG). 2013. Epidemiology

of Alzheimer's disease and other forms of dementia in China, 1990-2010: a systematic review and analysis.

Lancet 381(9882):2016-2023 DOI 10.1016/S0140-6736(13)60221-4.

Chin D, Huebbe P, Pallauf K, Rimbach G. 2013. Neuroprotective properties of curcumin in Alzheimer's

disease--merits and limitations. Current Medicinal Chemistry 20(32):3955-3985 DOI

$10.2174 / 09298673113209990210$.

Citron M. 2010. Alzheimer's disease: strategies for disease modification. Nature Reviews Drug Discovery

9(5):387-398 DOI 10.1038/nrd2896.

De-Paula VJ, Radanovic M, Diniz BS, Forlenza OV. 2012. Alzheimer's disease. Subcellular Biochemistry 65:329-352 DOI 10.1007/978-94-007-5416-4_14.

Dolgin E. 2017. The most popular genes in the human genome. Nature 551(7681):427-431 DOI 10.1038/d41586-017-07291-9.

Duan S, Guan X, Lin R, Liu X, Yan Y, Lin R, Zhang T, Chen X, Huang J, Sun X, Li Q, Fang S, Xu

J, Yao Z, Gu H. 2015. Silibinin inhibits acetylcholinesterase activity and amyloid $\beta$ peptide aggregation:

a dual-target drug for the treatment of Alzheimer's disease. Neurobiology of Aging 36(5):1792-1807 DOI 10.1016/j.neurobiolaging.2015.02.002.

Fu Z, Yang J, Wei Y, Li J. 2016. Effects of piceatannol and pterostilbene against $\beta$-amyloid-induced apoptosis on the PI3K/Akt/Bad signaling pathway in PC12 cells. Food \& Function 7(2):1014-1023 DOI $10.1039 / \mathrm{c} 5$ fo0 $01124 \mathrm{~h}$.

Goedert M, Spillantini MG. 2006. A century of Alzheimer's disease. Science 314(5800):777-781 DOI 
339

340

341

342

343

344

345

346

347

348

349

350

351

352

353

354

355

356

357

358

359

10.1126/science. 1132814 .

Guzior N, Wieckowska A, Panek D, Malawska B. 2015. Recent development of multifunctional agents as potential drug candidates for the treatment of Alzheimer's disease. Current Medicinal Chemistry 22(3):373-404 DOI 10.2174/0929867321666141106122628.

Hardy JA, Higgins GA. 1992. Alzheimer's disease: the amyloid cascade hypothesis. Science 256(5054):184-185 DOI 10.1126/science.1566067.

Jazvinšćak Jembrek M, Slade N, Hof PR, Šimić G. 2018. The interactions of p53 with tau and Aß as potential therapeutic targets for Alzheimer's disease. Progress in Neurobiology 168:104-127 DOI 10.1016/j.pneurobio.2018.05.001.

Jia J, Zhu F, Ma X, Cao Z, Cao ZW, Li Y, Li YX, Chen YZ. 2009. Mechanisms of drug combinations: interaction and network perspectives. Nature Reviews Drug Discovery 8(2):111-128 DOI 10.1038/nrd2683.

Jia J, Wang F, Wei C, Zhou A, Jia X, Li F, Tang M, Chu L, Zhou Y, Zhou C, Cui Y, Wang Q, Wang W, Yin P, Hu N, Zuo X, Song H, Qin W, Wu L, Li D, Jia L, Song J, Han Y, Xing Y, Yang P, Li Y, Qiao Y, Tang Y, Lv J, Dong X. 2014. The prevalence of dementia in urban and rural areas of China. Alzheimer's \& Dementia 10(1):1-9 DOI 10.1016/j.jalz.2013.01.012.

Jia J, Wei C, Chen S, Li F, Tang Y, Qin W, Zhao L, Jin H, Xu H, Wang F, Zhou A, Zuo X, Wu L, Han Y, Han Y, Huang L, Wang Q, Li D, Chu C, Shi L, Gong M, Du Y, Zhang J, Zhang J, Zhou C, Lv J, Lv Y, Xie H, Ji Y, Li F, Yu E, Luo B, Wang Y, Yang S, Qu Q, Guo Q, Liang F, Zhang J, Tan L, Shen L, Zhang K, Zhang J, Peng D, Tang M, Lv P, Fang B, Chu L, Jia L, Gauthier S. 2018. The cost of Alzheimer's disease in China and re-estimation of costs worldwide. Alzheimer's \& Dementia 14(4):483-491 DOI 10.1016/j.jalz.2017.12.006. 
360

361

362

363

364

365

366

367

368

369

370

371

372

373

374

375

376

377

378

379

380

Kim H, Youn K, Ahn MR, Kim OY, Jeong WS, Ho CT, Jun M. 2015. Neuroprotective effect of loganin

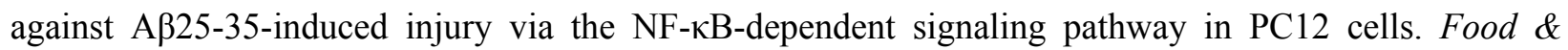
Function 6(4):1108-1116 DOI 10.1039/c5fo00055f.

Lehár J, Krueger AS, Avery W, Heilbut AM, Johansen LM, Price ER, Rickles RJ, Short GF 3rd, Staunton JE, Jin X, Lee MS, Zimmermann GR, Borisy AA. 2009. Synergistic drug combinations tend to improve therapeutically relevant selectivity. Nature Biotechnology 27(7):659-666 DOI 10.1038/nbt. 1549 .

Li L, Xu D, Lin J, Zhang D, Wang G, Sui L, Ding H, Du J. 2017. Coenzyme Q10 attenuated $\beta$ amyloid(25-35)-induced inflammatory responses in PC12 cells through regulation of the NF- $\mathrm{BB}$ signaling pathway. Brain Research Bulletin 131:192-198 DOI 10.1016/j.brainresbull.2017.04.014.

Limesand KH, Schwertfeger KL, Anderson SM. 2006. MDM2 is required for suppression of apoptosis by activated Akt1 in salivary acinar cells. Molecular and Cellular Biology 26(23):8840-8856 DOI 10.1128/MCB.01846-05.

Mattson MP. 2004. Pathways towards and away from Alzheimer's disease. Nature 430(7000):631-639 DOI 10.1038/nature02621.

Mattson MP. 2015. Late-onset dementia: a mosaic of prototypical pathologies modifiable by diet and lifestyle. NPJ Aging Mechanism \& Disease 1:15003 DOI 10.1038/npjamd.2015.3.

Mattson MP, Arumugam TV. 2018. Hallmarks of Brain Aging: Adaptive and Pathological Modification by Metabolic States. Cell Metabolism 27(6):1176-1199 DOI 10.1016/j.cmet.2018.05.011.

Meng J, Li Y, Camarillo C, Yao Y, Zhang Y, Xu C, Jiang L. 2014. The anti-tumor histone deacetylase inhibitor SAHA and the natural flavonoid curcumin exhibit synergistic neuroprotection against amyloid- 
381

382

383

384

385

386

387

388

389

390

391

392

393

394

395

396

397

398

399

400

401

beta toxicity. PLoS One 9(1):e85570 DOI 10.1371/journal.pone.0085570.

Ohyagi Y, Asahara H, Chui DH, Tsuruta Y, Sakae N, Miyoshi K, Yamada T, Kikuchi H, Taniwaki

T, Murai H, Ikezoe K, Furuya H, Kawarabayashi T, Shoji M, Checler F, Iwaki T, Makifuchi T,

Takeda K, Kira J, Tabira T. 2015. Intracellular Abeta42 activates p53 promoter: a pathway to neurodegeneration in Alzheimer's disease. FASEB Journal 19(2):255-257 DOI 10.1096/fj.04-2637fje.

Pate KM, Rogers M, Reed JW, van der Munnik N, Vance SZ, Moss MA. 2017. Anthoxanthin Polyphenols Attenuate A $\beta$ Oligomer-induced Neuronal Responses Associated with Alzheimer's Disease.

CNS Neuroscience \& Therapeutics 23(2):135-144 DOI 10.1111/cns.12659.

Potter PE. 2013. Curcumin: a natural substance with potential efficacy in Alzheimer's disease. Journal of Experimental Pharmacology 5:23-31 DOI 10.2147/JEP.S26803.

Ringman JM, Frautschy SA, Teng E, Begum AN, Bardens J, Beigi M, Gylys KH, Badmaev V, Heath

DD, Apostolova LG, Porter V, Vanek Z, Marshall GA, Hellemann G, Sugar C, Masterman DL,

Montine TJ, Cummings JL, Cole GM. 2012. Oral curcumin for Alzheimer's disease: tolerability and

efficacy in a 24-week randomized, double blind, placebo-controlled study. Alzheimer's Research \& Therapy

4(5):43 DOI 10.1186/alzrt146.

Rouaux C, Loeffler JP, Boutillier AL. 2004. Targeting CREB-binding protein (CBP) loss of function as a therapeutic strategy in neurological disorders. Biochemical Pharmacology 68(6):1157-1164 DOI 10.1016/j.bcp.2004.05.035.

Sanabria-Castro A, Alvarado-Echeverría I, Monge-Bonilla C. 2017. Molecular Pathogenesis of Alzheimer's Disease: An Update. Annals of Neurosciences 24(1):46-54 DOI 10.1159/000464422.

Sawmiller D, Li S, Shahaduzzaman M, Smith AJ, Obregon D, Giunta B, Borlongan CV, Sanberg PR, 
402

403

404

405

406

407

408

409

410

411

412

413

414

415

416

417

418

419

420

421

422

Tan J. 2014. Luteolin reduces Alzheimer's disease pathologies induced by traumatic brain injury.

International Journal of Molecular Sciences 15(1):895-904 DOI 10.3390/ijms15010895.

Song X, Liu B, Cui L, Zhou B, Liu W, Xu F, Hayashi T, Hattori S, Ushiki-Kaku Y, Tashiro SI,

Ikejima T. 2017. Silibinin ameliorates anxiety/depression-like behaviors in amyloid $\beta$-treated rats by

upregulating BDNF/TrkB pathway and attenuating autophagy in hippocampus. Physiology \& Behavior

179:487-493 DOI 10.1016/j.physbeh.2017.07.023.

Song X, Liu B, Cui L, Zhou B, Liu L, Liu W, Yao G, Xia M, Hayashi T, Hattori S, Ushiki-Kaku Y,

Tashiro SI, Ikejima T. 2018. Estrogen Receptors Are Involved in the europrotective Effect of Silibinin in

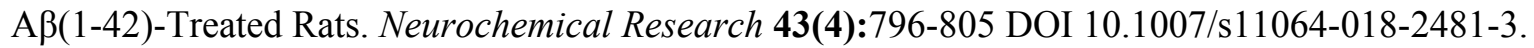

Tiwari SK, Agarwal S, Seth B, Yadav A, Nair S, Bhatnagar P, Karmakar M, Kumari M, Chauhan

LK, Patel DK, Srivastava V, Singh D, Gupta SK, Tripathi A, Chaturvedi RK, Gupta KC. 2014.

Curcumin-loaded nanoparticles potently induce adult neurogenesis and reverse cognitive deficits in

Alzheimer's disease model via canonical Wnt/ $\beta$-catenin pathway. ACS Nano 8(1):76-103 DOI

$10.1021 / \mathrm{nn} 405077 \mathrm{y}$.

Vázquez de la Torre A, Junyent F, Folch J, Pelegrí C, Vilaplana J, Auladell C, Beas-Zarate C, Pallàs

M, Verdaguer E, Camins A. 2013. PI3 k/akt inhibition induces apoptosis through p38 activation in neurons. Pharmacological Research 70(1):116-125 DOI 10.1016/j.phrs.2013.01.007.

Venigalla M, Gyengesi E, Münch G. 2015. Curcumin and Apigenin - novel and promising therapeutics against chronic neuroinflammation in Alzheimer's disease. Neural Regeneration Research 10(8):1181-

1185 DOI 10.4103/1673-5374.162686.

Wang H, Jiang T, Li W, Gao N, Zhang T. 2018. Resveratrol attenuates oxidative damage through 
423

424

425

426

427

428

429

430

431

432

433

434

435

436

437

438

439

440

441

442

443

activating mitophagy in an in vitro model of Alzheimer's disease. Toxicology Letters 282:100-108 DOI

10.1016/j.toxlet.2017.10.021.

Westmark CJ, Westmark PR, Malter JS. 2013. Soy-based diet exacerbates seizures in mouse models of neurological disease. Journal of Alzheimers Disease 33(3):797-805 DOI 10.3233/JAD-2012-121426.

You F, Li Q, Jin G, Zheng Y, Chen J, Yang H. 2017. Genistein protects against A $\beta(25-35)$ induced apoptosis of PC12 cells through JNK signaling and modulation of Bcl-2 family messengers. $B M C$ Neuroscience 18(1):12 DOI 10.1186/s12868-016-0329-9.

Zhao L, Wang JL, Wang YR, Fa XZ. 2013. Apigenin attenuates copper-mediated $\beta$-amyloid neurotoxicity through antioxidation, mitochondrion protection and MAPK signal inactivation in an AD cell model. Brain Research 1492:33-45 DOI 10.1016/j.brainres.2012.11.019.

Zhao L, Zhu L, Guo X. 2018. Valproic acid attenuates A $\beta(25-35)$-induced neurotoxicity in PC12 cells through suppression of mitochondria-mediated apoptotic pathway. Biomedicine \& Pharmacotherapy 106:77-82 DOI 10.1016/j.biopha.2018.06.080.

Zimmermann GR, Lehár J, Keith CT. 2007. Multi-target therapeutics: when the whole is greater than the sum of the parts. Drug Discovery Today 12(1-2):34-42 DOI 10.1016/j.drudis.2006.11.008.

\section{FIGURE LEGENDS}

Figure 1. CVS treatment inhibits $\mathbf{A} \boldsymbol{\beta}_{25-35}$-induced PC12 cell apoptosis. A. Individual effects of 9 candidate compounds on cell viability of $\mathrm{A} \beta_{25-35}$-treated PC12 cells. B-D. Effects of CVS on cell viability (B), reversion of CASP3 expression (C), and apoptotic cell levels (D) in A $\beta_{25-35}$-treated PC12 cells. Each experiment was completed with a minimum of 5 replicates. Statistical significance is presented as; \#\# $p<$ 
4440.001 versus $\mathrm{Ctrl} ;{ }^{*} p<0.01,{ }^{*}{ }^{*} p<0.001$ versus $\mathrm{A} \beta$. Abbreviations: A $\beta, \mathrm{A} \beta_{25-35}$ treatment group; C,

445 curcumin and $\mathrm{A} \beta_{25-35}$ treatment group; CASP3, Caspase 3, Ctrl, control group; CV, curcumin, vorinostat

446 and $A \beta_{25-35}$ treatment group; CVS, curcumin, vorinostat, silibinin and $\mathrm{A} \beta_{25-35}$ treatment group.

447 Figure 2. CVS pretreatment prevents $\mathbf{A} \boldsymbol{\beta}_{25-35}$-induced oxidative stress in PC12 cells. A-C. Effects of 448 CVS on ROS (A), SOD (B), and MDA levels (C). Each experiment was completed with a minimum of 5 replicates. Statistical significance is presented as; \#\# $p<0.001$ versus Ctrl; ${ }^{*} p<0.01, * * p<0.001$ versus $\mathrm{A} \beta$. Ctrl: control group; $\mathrm{A} \beta: \mathrm{A} \beta_{25-35}$ treatment group. Abbreviations: $\mathrm{A} \beta, \mathrm{A} \beta_{25-35}$ treatment group; $\mathrm{C}$, curcumin and $\mathrm{A} \beta_{25-35}$ treatment group; Ctrl, control group; $\mathrm{CV}$, curcumin, vorinostat and $\mathrm{A} \beta_{25-35}$ treatment group; CVS, curcumin, vorinostat, silibinin and $\mathrm{A} \beta_{25-35}$ treatment group.

Figure 3. Effects of CVS pretreatment on the expression of critical proteins. A-C. Effects of CVS on

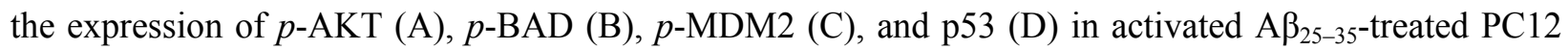
cells. Each experiment was completed with a minimum of 5 replicates. Statistical significance is presented as; \#\# $p<0.001$ versus Ctrl; ${ }^{*} p<0.01,{ }^{* *} p<0.001$ versus $\mathrm{A} \beta$. Abbreviations: $\mathrm{A} \beta, \mathrm{A} \beta_{25-35}$ treatment group; $\mathrm{AKT}, \mathrm{AKT}$ serine/threonine kinase; BAD, BCL2 associated agonist of cell death; $\mathrm{C}$, curcumin and $\mathrm{A} \beta_{25-35}$ treatment group; $\mathrm{Ctrl}$, control group; $\mathrm{CV}$, curcumin, vorinostat and $\mathrm{A} \beta_{25-35}$ treatment group; $\mathrm{CVS}$, curcumin, vorinostat, silibinin and $A \beta_{25-35}$ treatment group; MDM2, MDM2 proto-oncogene 2; p53, tumor protein p53.

Figure 4. CVS reduced the intranuclear content of $\mathbf{p 5 3}$ in $\mathrm{A \beta}_{25-35}$-treated PC12 cells. Each experiment $\mathrm{Ctrl} ;{ }^{*} p<0.01,{ }^{* *} p<0.001$ versus $\mathrm{A} \beta$. Abbreviations: $\mathrm{A} \beta, \mathrm{A} \beta_{25-35}$ treatment group; $\mathrm{C}$, curcumin and $\mathrm{A} \beta_{25-}$ 35 treatment group; Ctrl, control group; $\mathrm{CV}$, curcumin, vorinostat and $\mathrm{A} \beta_{25-35}$ treatment group; CVS, 
465 curcumin, vorinostat, silibinin and $\mathrm{A} \beta_{25-35}$ treatment group. 


\section{Figure 1}

CVS treatment inhibits $A \beta_{25-35}$-induced PC12 cell apoptosis.

A. Individual effects of 9 candidate compounds on cell viability of $A \beta_{25-35}$-treated PC12 cells.

B-D. Effects of CVS on cell viability (B), reversion of CASP3 expression (C), and apoptotic cell levels (D) in $A \beta_{25-35}$-treated PC12 cells. Each experiment was completed with a minimum of 5 replicates. Statistical significance is presented as; $\# \# p<0.001$ versus $\mathrm{Ctrl} ; * p<0.01$, ** $p$ $<0.001$ versus $A \beta$. Abbreviations: $A \beta, A \beta_{25-35}$ treatment group; $C$, curcumin and $A \beta_{25-35}$ treatment group; CASP3, Caspase 3, Ctrl, control group; CV, curcumin, vorinostat and $A \beta_{25-35}$ treatment group; $C V S$, curcumin, vorinostat, silibinin and $A \beta_{25-35}$ treatment group. 

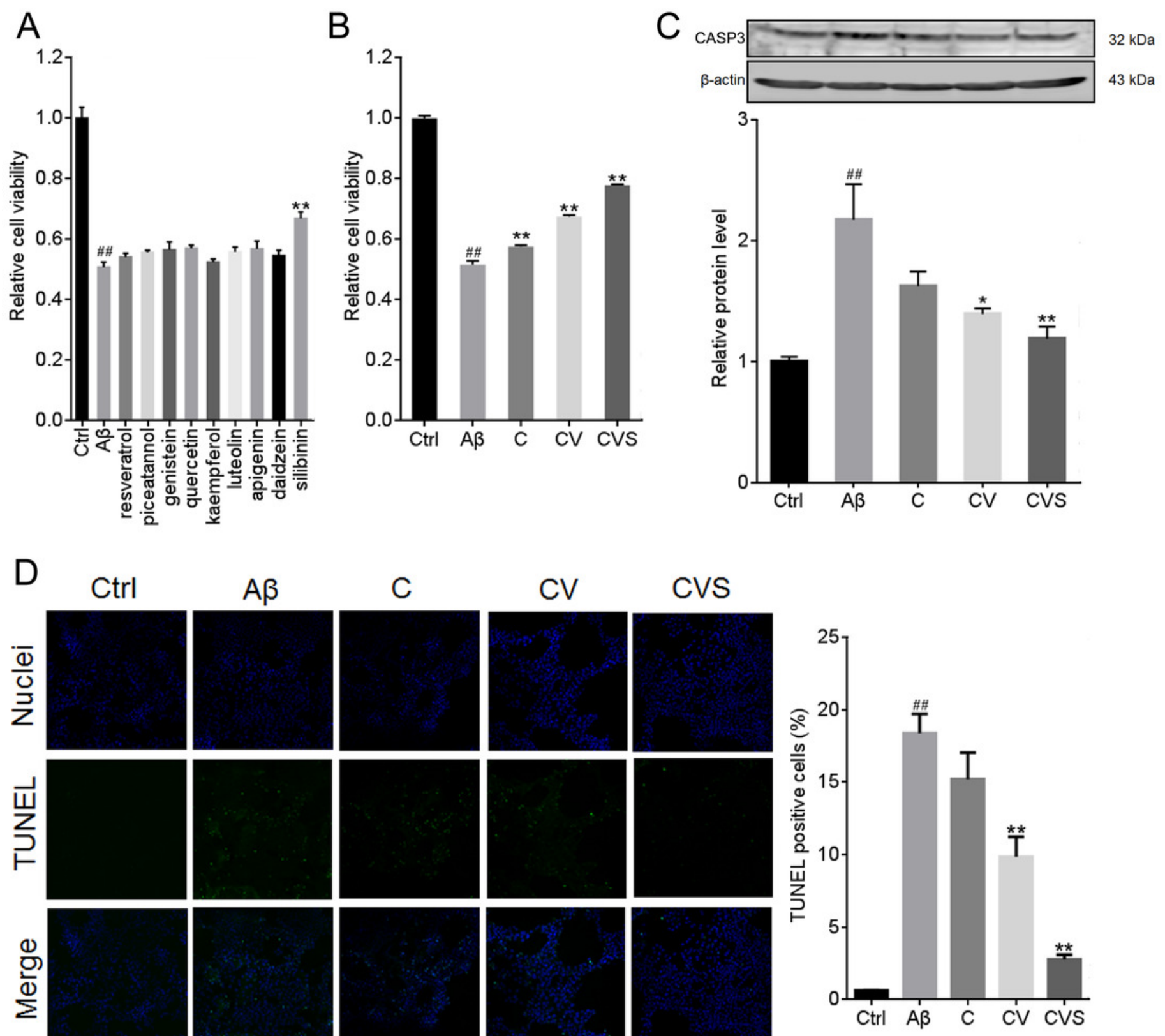


\section{Figure 2}

CVS pretreatment prevents $A \beta_{25-35}$-induced oxidative stress in PC12 cells.

A-C. Effects of CVS on ROS (A), SOD (B), and MDA levels (C). Each experiment was completed with a minimum of 5 replicates. Statistical significance is presented as; \#\# $p<$ 0.001 versus Ctrl; $* p<0.01, * * p<0.001$ versus $A \beta$. Ctrl: control group; $A \beta$ : $A \beta_{25-35}$ treatment group. Abbreviations: $A \beta, A \beta_{25-35}$ treatment group; $C$, curcumin and $A \beta_{25-35}$ treatment group; Ctrl, control group; $C V$, curcumin, vorinostat and $A \beta_{25-35}$ treatment group; CVS, curcumin, vorinostat, silibinin and $A \beta_{25-35}$ treatment group.

A
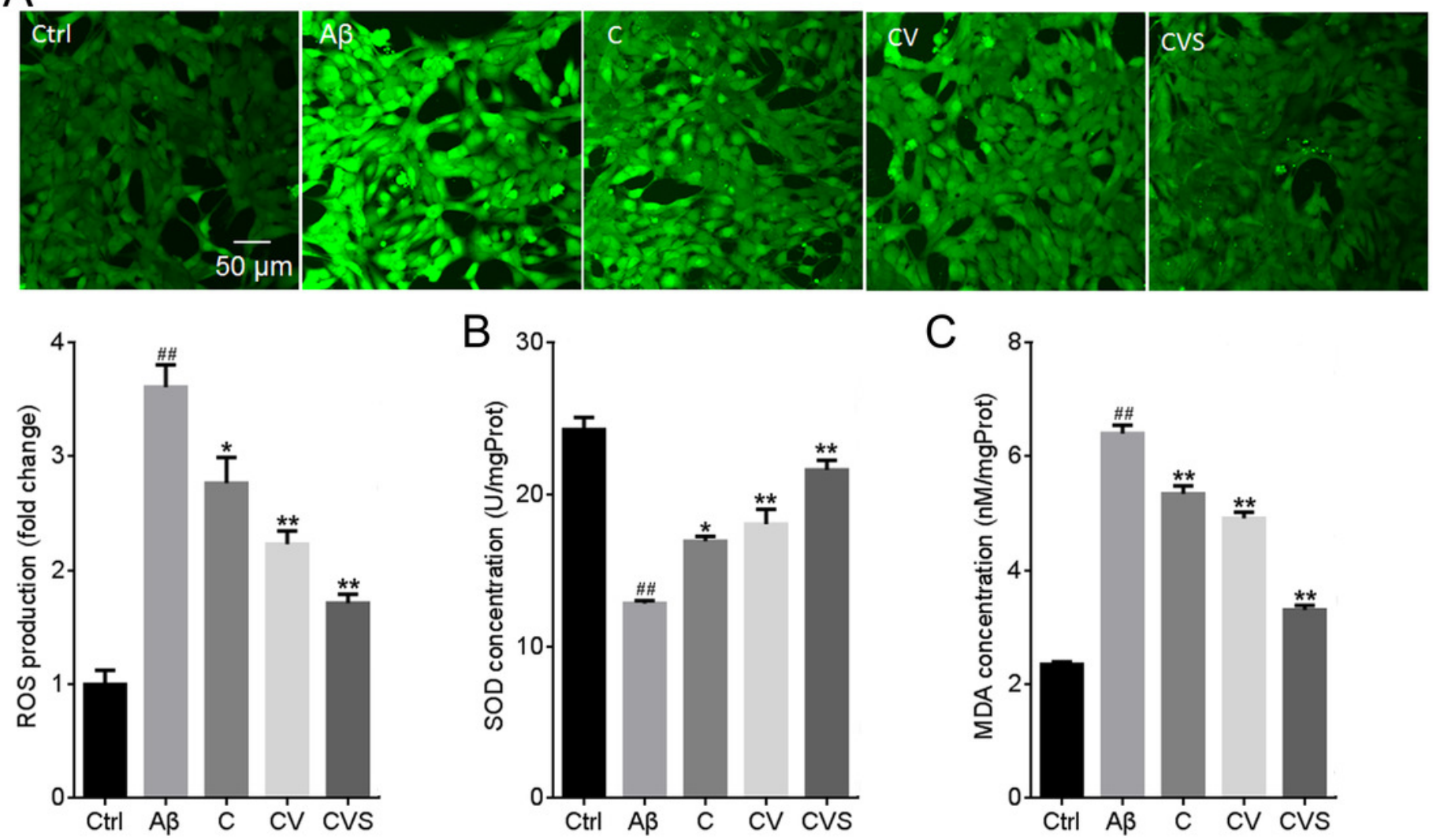

C

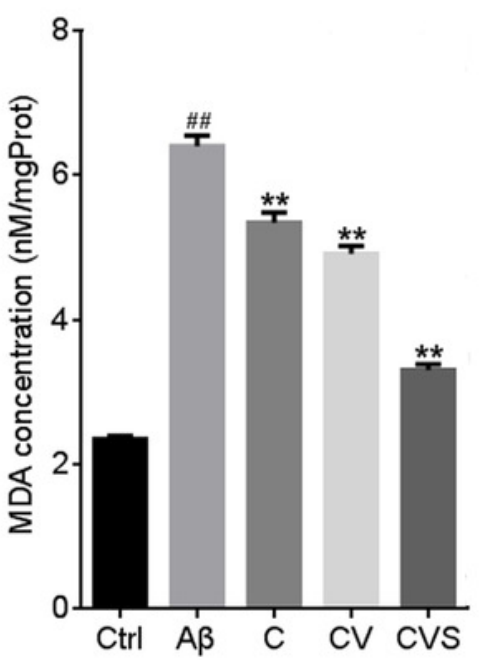




\section{Figure 3}

Effects of CVS pretreatment on the expression of critical proteins.

A-C. Effects of CVS on the expression of p-AKT (A), p-BAD (B), p-MDM2 (C), and p53 (D) in activated $A \beta_{25-35}$-treated $P C 12$ cells. Each experiment was completed with a minimum of 5 replicates. Statistical significance is presented as; $\# \# p<0.001$ versus $\mathrm{Ctrl} ; * p<0.01, * * p$ $<0.001$ versus $A \beta$. Abbreviations: $A \beta, A \beta_{25-35}$ treatment group; $A K T$, $A K T$ serine/threonine kinase; $B A D, B C L 2$ associated agonist of cell death; $C$, curcumin and $A \beta_{25-35}$ treatment group; $\mathrm{Ctrl}$, control group; $\mathrm{CV}$, curcumin, vorinostat and $A \beta_{25-35}$ treatment group; CVS, curcumin, vorinostat, silibinin and $A \beta_{25-35}$ treatment group; MDM2, MDM2 proto-oncogene 2; p53, tumor protein $\mathrm{p} 53$. 
A
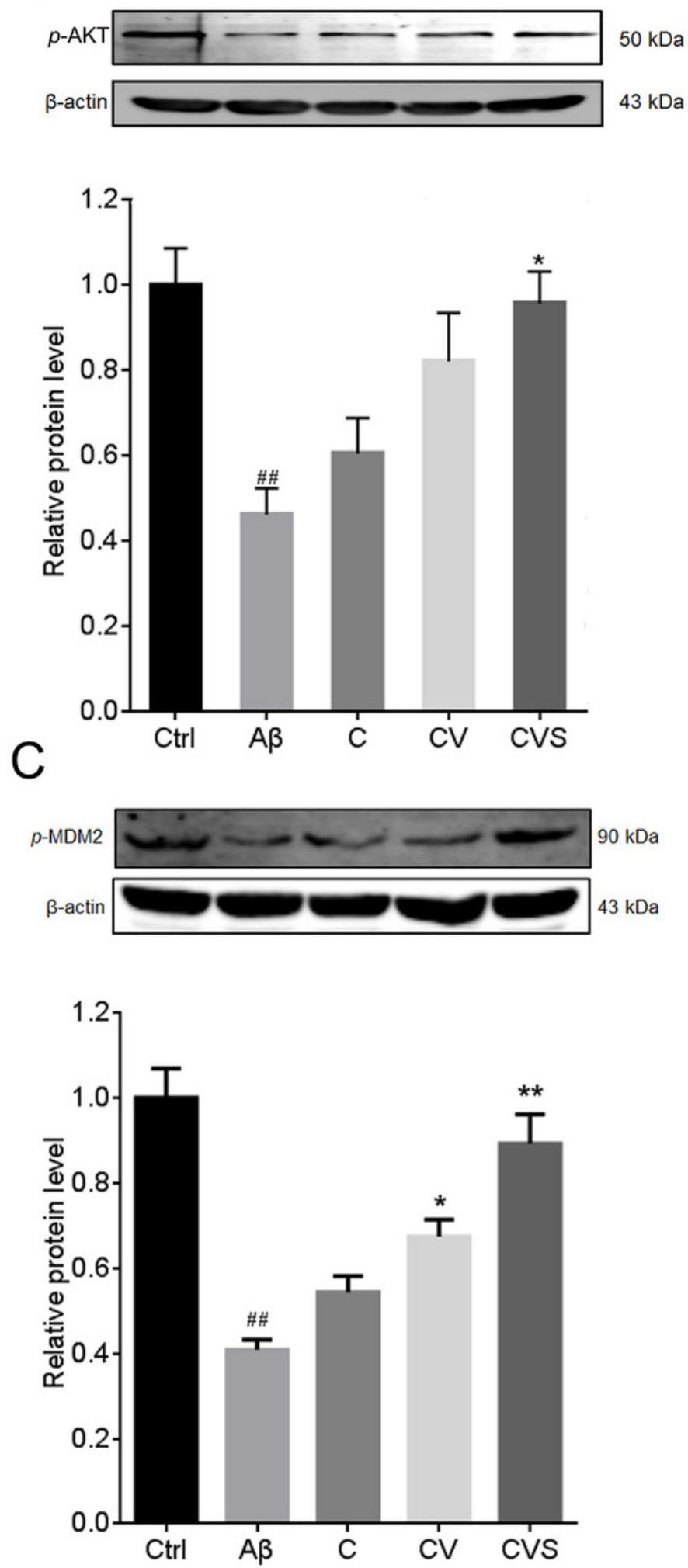

B
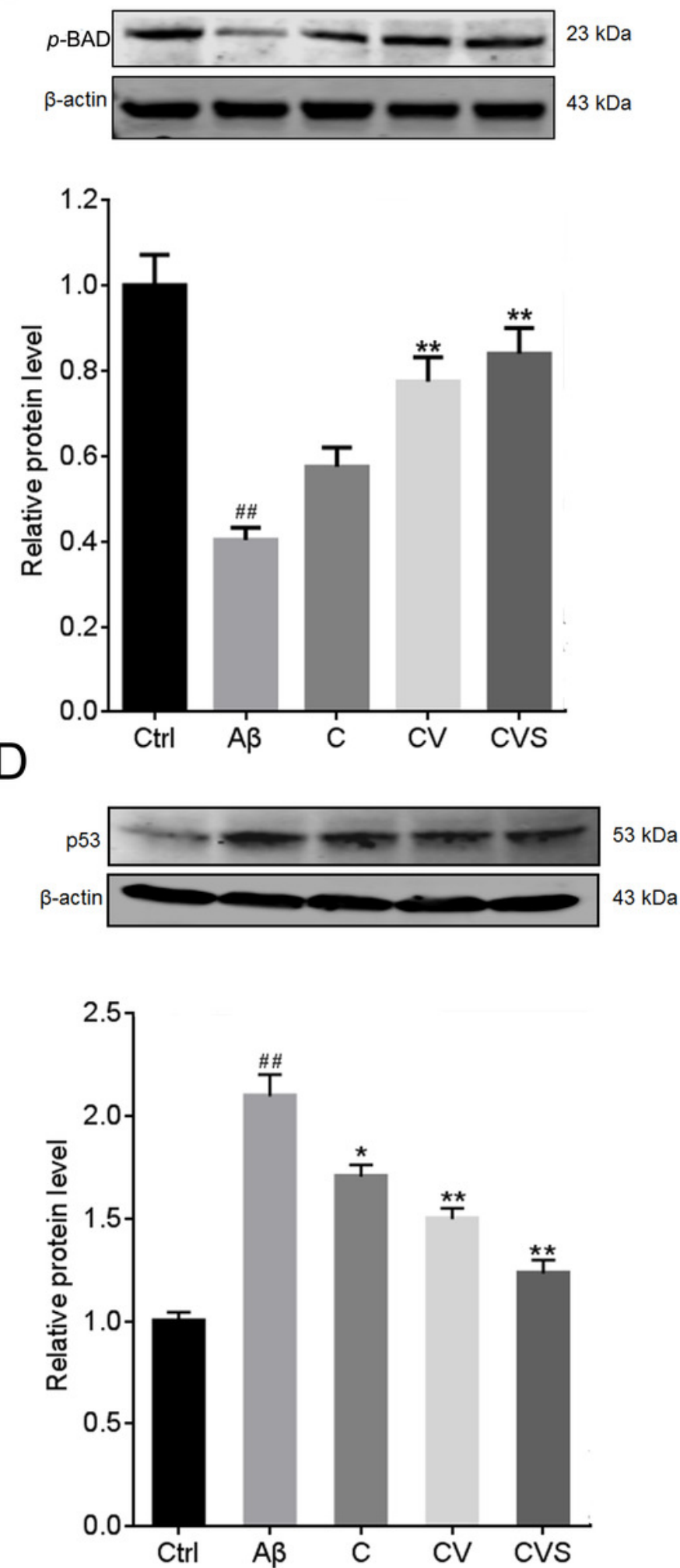


\section{Figure 4}

CVS reduced the intranuclear content of p53 in $A \beta_{25-35}$-treated PC12 cells.

Each experiment was completed with a minimum of 5 replicates. Statistical significance is presented as; \#\# $p<0.001$ versus $\mathrm{Ctrl} ;{ }^{*} p<0.01,{ }^{* *} p<0.001$ versus $\mathrm{A} \beta$. Abbreviations: $A \beta, A \beta_{25-35}$ treatment group; $C$, curcumin and $A \beta_{25-35}$ treatment group; $C t r l$, control group; $C V$, curcumin, vorinostat and $A \beta_{25-35}$ treatment group; CVS, curcumin, vorinostat, silibinin and $A \beta_{25-35}$ treatment group.

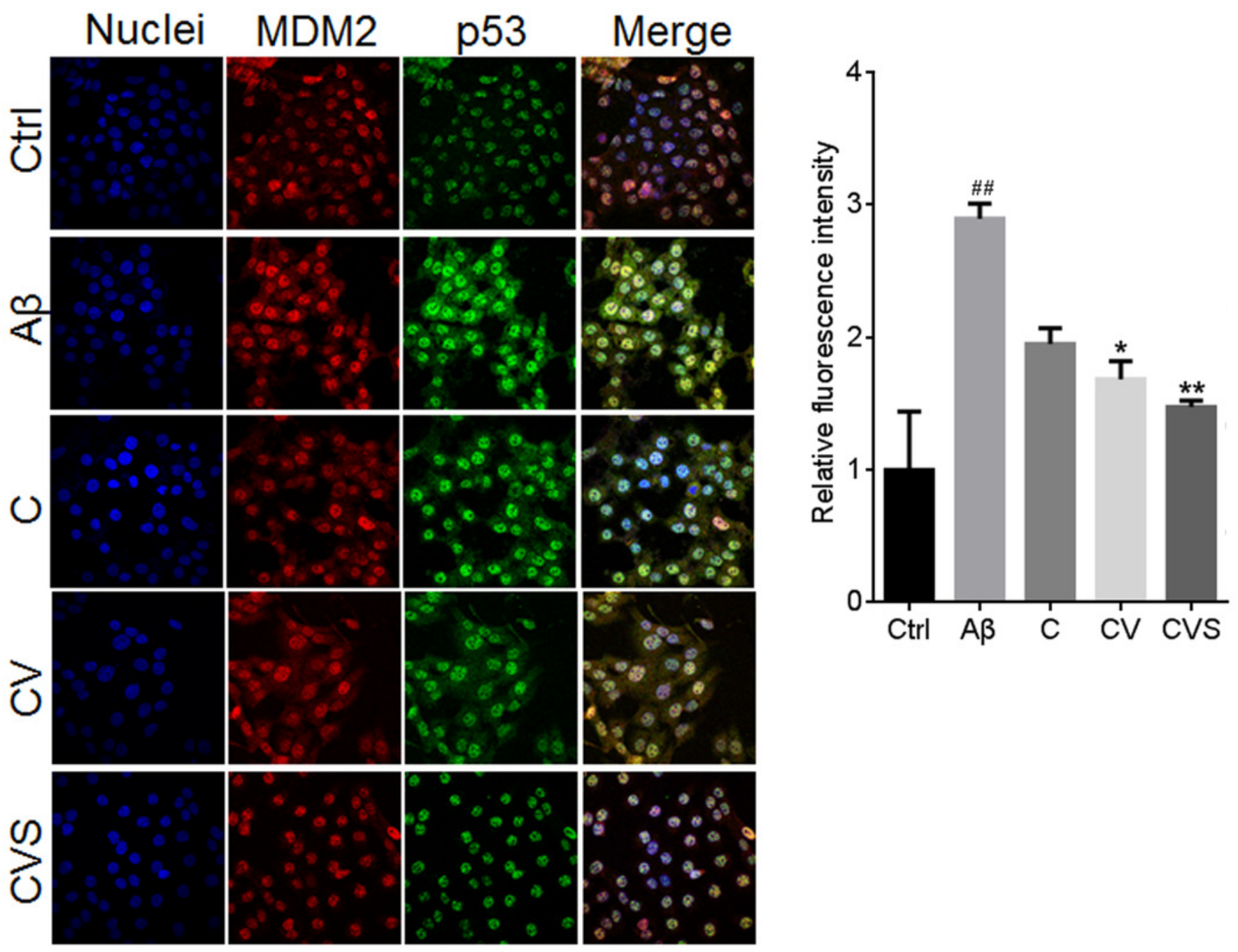

